\title{
Fasting motor activity occurs during a day of normal meals in healthy subjects
}

\author{
D G THOMPSON, LORNA ARCHER, W J GREEN, and D L WINGATE* \\ Fron the Department of Gastrointestinal Science, London Hospital Medical College, London
}

SUMMARY Using a radiotelemetric technique of pressure recording which did not interfere with normal feeding, jejunal motor activity was recorded in seven healthy human subjects, who were given three hospital meals during the course of a day, and allowed ad libitum supplementary snacks. Fasting motor activity was detected during the day in five subjects, and, although its occurrence was very variable, tended to occur shortly before the next meal.

Periodic motor activity of the stomach and intestine, present during fasting and interrupted by feeding, was fully documented many years ago. $^{1}$ We have described ${ }^{2}$ a minimally-invasive radiotelemetric technique for recording of patterns of human jejunal motor activity, which does not prevent normal feeding, and which is sufficiently comfortable for prolonged continuous observation. Using this technique, we have documented the incidence of cyclical jejunal motor activity in healthy human subjects during a 24 hour fast, and the interruption of this pattern by a single meal.

No data have been published to show the extent to which migrating complexes occur during a normal day in healthy adults. It seemed reasonable to suppose that, given the frequency of nutrient intake in everyday life, the occurrence of fasting motor activity in man must be confined to the night. Support for this belief derives from a study ${ }^{4}$ showing that the stomach does not usually empty completely between meals during the day, and also from our own data ${ }^{2}$ which showed the median interval in healthy subjects between the start of a meal and the reappearance of recognisable jejunal fasting motor activity to be more than five hours. We now report the experimental testing of this supposition.

\section{Methods}

Seven healthy subjects (age 20-26 years) free of gastrointestinal symptoms, who had given informed consent, swallowed on the evening of

*Address for reprint requests: Dr D L Wingate, London Hospital, Whitechapel Road, London E1 1BB, England.

Received for publication 12 December 1980 study a miniature $(8 \mathrm{~mm}$ diameter, $22 \mathrm{~mm}$ length) radiotelemetric pressure transducer (Rigel $\mathrm{Re}$ search Ltd) attached to a $100 \mathrm{~cm}$ thread. The lower end of the thread was enclosed in a radioopaque flexible sleeve. The next morning, using an X-ray image intensifier and traction on the thread if necessary, its position was adjusted so that it lay just distal to the duodeno-jejunal flexure; the thread was then secured to the subject's face with adhesive tape. An aerial array was fastened around the subject's waist and connected to a receiver tuned to $450 \mathrm{KHz}$. Subjects were then given standard hospital meals (Table) during the study, and, in between meals, were allowed free access to coffee, tea, apples, and biscuits. After the evening meal, the subjects spent the night in the study unit (in one study the tape reco:der failed during the night) until breakfast on the following day when recording was stopped and the 'radio-pill' was withdrawn. The recorded signal was replayed, and fasting activity was considered to have reappeared when bursts of regular contractions at $10-11 /$ minute lasting not less than three minutes followed by quiescence ${ }^{3}$ were seen on the record (Fig. 1). Protocols for the study of gastrointestinal motor activity using ingested probes were approved by the Ethics Committee of the London Hospital Medical College in February 1975.

\section{Results}

Figure 2 shows the incidence of activity fronts in relation to meals and snacks in all seven studies. Two subjects noted sensations of hunger, neither of which coincided with complexes. In five subjects, complexes were seen between breakfast 
Table Composition of standard hospital meals

\begin{tabular}{|c|c|c|c|c|c|c|}
\hline Constituents & Meal & $\begin{array}{l}\text { Protein } \\
(g)\end{array}$ & $\begin{array}{l}\text { Fat } \\
(g)\end{array}$ & $\begin{array}{l}\text { Carbohydrate } \\
(g)\end{array}$ & megaJ & (kcal) \\
\hline $\begin{array}{l}\text { Cornflakes with milk, boiled egg, bread, } \\
\text { butter, marmalade }\end{array}$ & Breakfast & $18 \cdot 3$ & $18 \cdot 9$ & $56 \cdot 8$ & $1 \cdot 97$ & $(471)$ \\
\hline $\begin{array}{l}\text { Chicken, peas, mashed potato, stewed fruit } \\
\text { with custard }\end{array}$ & Lunch & $30 \cdot 2$ & $23 \cdot 9$ & $61 \cdot 5$ & 2.43 & $(582)$ \\
\hline $\begin{array}{l}\text { Chicken, peas, mashed potato, ice cream, } \\
\text { crackers, butter, cheddar cheese }\end{array}$ & Supper & $23 \cdot 9$ & $35 \cdot 5$ & $41 \cdot 9$ & $2 \cdot 86$ & $(603)$ \\
\hline
\end{tabular}

Calorific value of snack supplements estimated as $0-1 \cdot 55$ megaJ $(0-370 \mathrm{kcal})$.

and supper; out of the 10 complexes recorded during this time, six shortly preceded a meal and two preceded the consumption of a snack.

\section{Discussion}

The results of this study dismiss the notion that fasting motor complexes in man are only a nocturnal phenomenon. The variability between individuals which we have previously documented $^{2}$ is again demonstrated. The extent to which the variation relates to rates of gastric emptying cannot be assessed from our studies; the dependence of emptying rate on the composition of a meal is well recognised, but, even with similar meals, the data are confused. For example, it has been reported $^{4}$ that emptying of a homogenised meal is complete in $178 \pm 14$ minutes (mean \pm SEM), compared with $220 \pm 11$ minutes for a solid-liquid meal, but earlier studies from the same laboratory ${ }^{3}$ had shown that, with a formula meal of similar nutrient and caloric value, subjects showed $100 \%$ emptying only after six hours.

This study is open to criticism on the grounds that a hospital diet is not 'normal'. The variation in nutrient intake in individuals from day to day makes it difficult to define a diet which is normal for an individual, and more so for a population sample. The diet in this study, while neither gourmand nor gourmet, is within the normal range of intake in the population. ${ }^{5}$

Because the technique employed was a single sensor, we cannot be certain that all the periods
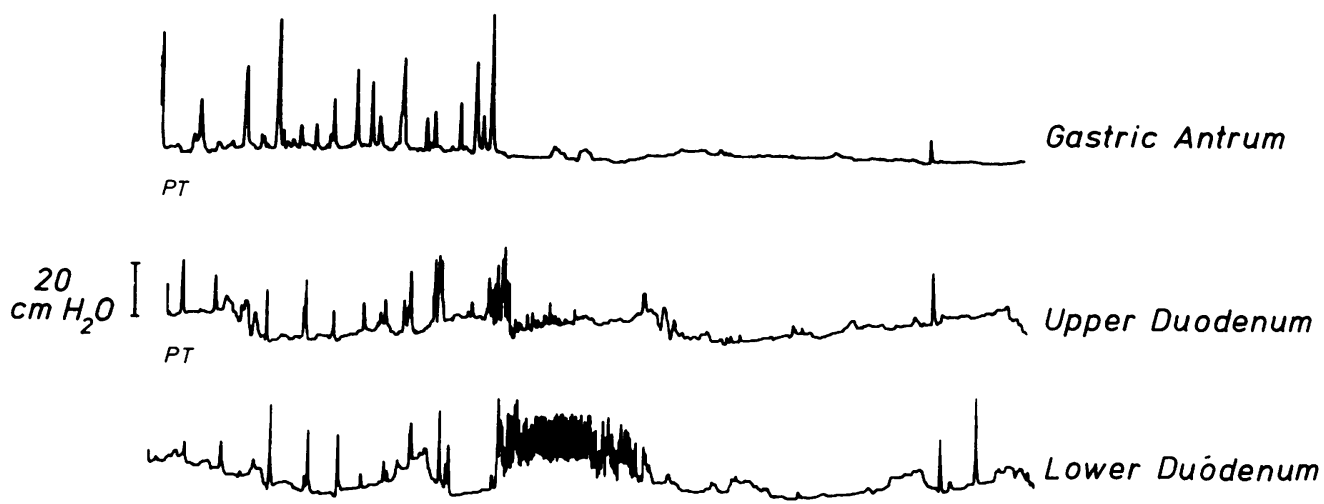

PT

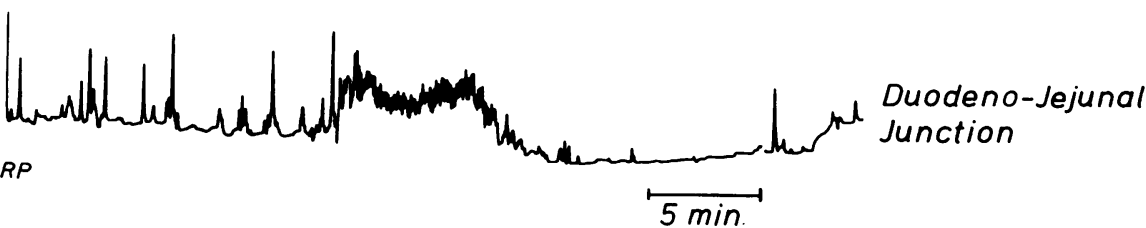

Fig. 1 Recording of a human fasting migratory complex by four sensors spaced at $10 \mathrm{~cm}$ intervals in the proximal digestive tract. The upper three sensors were perfused tubes (PT) with attached transducers, and the distal sensor (RP) was a radio-pill. Inspection of the bottom line alone shows the easily-identifiable appearance of a migrating complex passing the radio-pill. 


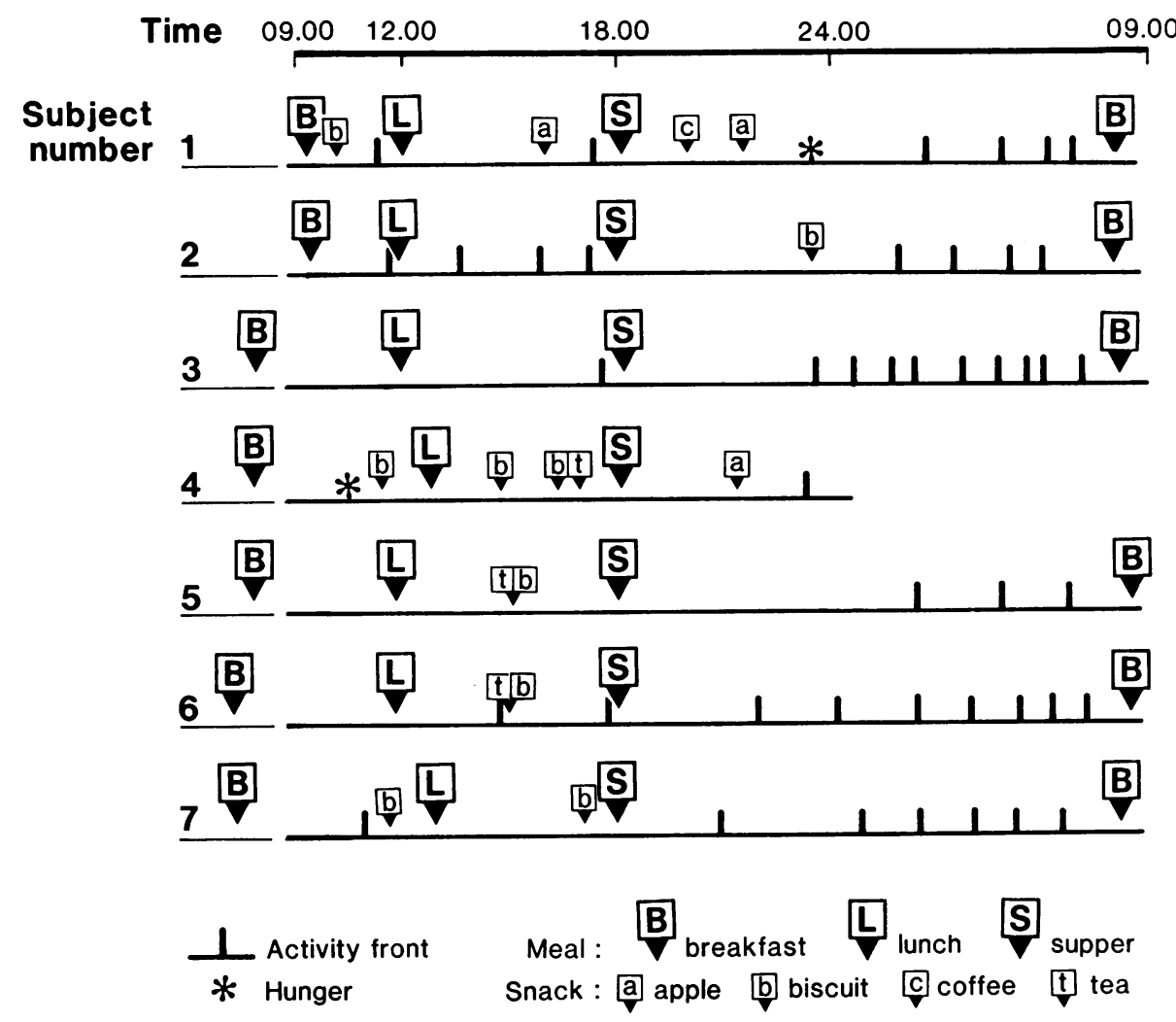

Fig. 2 Temporal relationship between food intake and the incidence of activity fronts in seven subjects. Horizontal lines indicate the duration of continuous recording.

of regular $11 / \mathrm{min}$ contractile activity represented phase III periods of a migrating complex, but we know of no reported evidence that periods of regular $11 / \mathrm{min}$ activity followed by quiescence have not been propagated, even if only over relatively short distances. Even conventional perfused tube systems, usually covering $50 \mathrm{~cm}$ segments, ${ }^{6}$ do not indicate whether complexes traverse the entire small bowel.

Similarly, we cannot be certain that all the complexes detected in our study were gastric as well as jejunal, but it seems likely that most of the complexes detected in the proximal jejunum are also present in the stomach. ${ }^{6}$ That the proximal jejunum is the optimal site for the detection of complexes is suggested by another study $^{7}$ in which complexes appeared to fade out in their passage along the jejunum, but the precise incidence of complexes at all levels of the small bowel and the distance over which they migrate remains to be described. Clinically, the secretory component of the complex may be equally, or more, significant than the motor component, as it is known that, in man, increased gastric acid secretion is normally associated with the active phase of periodic fasting motor activity. ${ }^{8-10}$ One inference that may be drawn from our data is that the traditional ulcer regime of frequent meals and antacids and anticholinergics may be helpful in the suppression of fasting secretory and motor activity during the day.

We wish to thank Ms Humpherson and the Dietetic Department of the London Hospital for providing meals, $\mathrm{Mr} \mathrm{W}$ Dobinson and Sister $\mathbf{M}$ Keenan for assistance, Ms Joan Abbott for preparing Fig. 2, and Ms Lynda Randall for typing. L $A$ and $W \quad J$ G are medical students at the London Hospital Medical College. Financial assistance from The Wellcome Trust, The Mason Medical Foundation, and Oxford Medical Electronics is gratefully acknowledged. 


\section{References}

${ }^{1}$ Boldyreff WN. Fonction periodique de l'organisme chez l'homme et les animaux d'ordre superieur (Pancreas comme principal agent du processus de l'assimilation dans tout le corps). $Q J$ Exp Physiol 1916; 10:175-201.

2Thompson DG, Wingate DL, Archer L, Benson MJ, Green WJ, Hardy RJ. Normal patterns of human upper small bowel activity recorded by prolonged radiotelemetry. Gut 1980; 21:500-6.

${ }^{3}$ Brunner H, Northfield TC, Hof mann AF, Go VLW, Summerskill WHJ. Gastric emptying and secretion of bile acids, cholesterol, and pancreatic enzymes during digestion: duodenal perfusion studies in healthy subjects. Mayo Clin Proc 1974; 49:851-60.

${ }^{4}$ Malagelada JR, Go VLW, Summerskill WHJ. Different gastric, pancreatic, and biliary responses to solid-liquid or homogenized meals. Dig Dis Sci 1979; 24:101-10.

${ }^{5}$ Department of Health and Social Security. Recommended daily amounts of food energy and nutrients for groups of people in the UK. DHSS report on health and social subjects, No 15. London: HMSO, 1979.

'Vantrappen G, Janssens J, Hellemans J, Ghoos Y. The inter-digestive motor complex of normal subjects and patients with bacterial overgrowth of the small intestine. J Clin Invest 1977; 59:1158-66.

${ }^{7}$ Fleckenstein P, Krogh F, Oigaard A. The interdigestive myoelectrical complex and other migrating electrical phenomena in the human small intestine. In: Duthie H, ed. Gastrointestinal motility in health and disease. Lancaster: MTP Press, 1978: 19-28.

${ }^{8}$ Hoelzel F. The relation between the secretory and motor activity in the fasting stomach (man). Am J Physiol 1925; 73:463-9.

${ }^{9}$ Hellebrandt FA. The relation between the motor and secretory function of the human stomach. $\mathrm{Am}$ J Physiol 1935; 112:162-5.

10Vantrappen GR, Peeters TL, Janssens J. The secretory component of the interdigestive migrating motor complex in man. Scand J Gastroenterol 1979; 14:663-7. 